\title{
Development of a New Hybrid Adsorbent Based on Polyaniline@Chitosan and Its Application to Acetaminophen Removal From Aqueous Solution
}

\section{Samia Daikh}

Faculté des Sciences et Thechnologie

\section{Dalila Ouis}

Faculté des Sciences et Thechnologie

Benyoucef Abdelghani ( $\sim$ abdelghani@ua.es )

Faculté des Sciences et Thechnologie https://orcid.org/0000-0002-0247-2808

Benali Mouffok

Faculté des Sciences et Thechnologie

\section{Research Article}

Keywords: Chitosan, Polyaniline, Acetaminophen, Adsorption, Isotherms, Kinetics

Posted Date: January 17th, 2022

DOI: https://doi.org/10.21203/rs.3.rs-1247688/v1

License: (c) (i) This work is licensed under a Creative Commons Attribution 4.0 International License. Read Full License 


\section{Abstract}

The polyaniline (PANI) with chitosan (CS) (PANI@CS) was synthesized using in-situ polymerization process and its preparation was assured by surface area, XPS, TPD, XRD, FTIR, TGA and SEM analysis. PANI@CS, CS and PANI were used for the removal of acetaminophen (AAP). The maximum value of

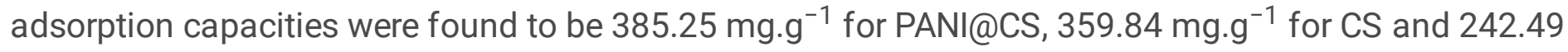
$\mathrm{mg} . \mathrm{g}^{-1}$ for PANI which reveal that the adsorption capacity of hybrid adsorbent is major than CS and PANI respectively. Moreover, $\mathrm{H}$-bonding, $\pi-\pi$ bonding, pore-filling and chemisorption have been suggested as probable mechanism for the elimination of AAP by PANI@CS. Furthermore, AAP elimination was preferable at pH 7.0. Pseudo-second-order (PSO) and Langmuir models reported the kinetic and isotherm data acceptably. This shows that the adsorption processes of AAP are a monolayer chemical adsorption, and it was endothermic, spontaneous, and favorable for the three adsorbents. Moreover, when reused, the hybrid adsorbent remains at around $69 \%$ of their original capacities after five adsorption cycles.

\section{Introduction}

Pharmaceutical composites (PhCs) are renowned emerging environmental contaminants that have been widely used for human and animals' therapy [1]. These products related to irregular consuming have been discovered in the environment [2]. Although of the consumption, PhCs disposal and effluents of unutilized and expired medicine have a significant role to introduce the medicaments into the environment [3]. Today, the existence of PhCs as potential sources of water and waste water has become a significant attention [4]. In spite, the concentrations of PhCs in waste water are considerably found in $\mu \mathrm{g} . \mathrm{L}^{-1}$ grades, but in waste water purification plants with influent from PhCs manufacturing, the quantity of these products has been found up to several ppm [5]. Classical water and waste water purifying techniques have no fundamental impacts on the PhCs elimination and subsequently rest intact in environment [4].

Out of varied other emerging pollutants is acetaminophen (AAP), In contrast called; an paracetamol or acylated amide medicine. AAP is one of the most considerably used antipyretics, painkillers and soreness relieving medicines throughout the world as a first line medicine due to it is effective, inexpensive and comparatively has low side impacts [6-8]. AAP is widely rejected into water body via elimination of unutilized hospital wastes and processing effluent discharges. AAP is however famous for its cumulating in aquatic organisms and around $59-69 \%$ of the consumed medicine is transferred out into available water bodies in the form of urine $[6,7]$.

In literature various studies have reported different methods of waste water treatments, such as ultrafiltration electro-dialysis [9], reverse osmosis [10], Fenton based process [11], and adsorption [12]. Amongst these, investigators have display an growing attention in the adsorption method because it is a highly efficient process, low-cost and energy. Conversely most other methods such as that comprising advanced oxidation process, adsorption is unable of degrading pollutant and creating highest toxic species. 
The use of Chitosan (CS) for the preparation of adsorbent composite, due to its increased adsorption abilities, is at its peak nowadays and many researchers worldwide focus on their synthesis. In contrast, some observable obstacle of bare CS, contain low porosity, sensitivity to $\mathrm{pH}$ changes, reduced surface area and difficulty in renewal post course of processing [13], undermined its industrial scale applications. One approach to exceed these disadvantages is to dope two or more appropriate polymers, which demonstrated that the doping ameliorates resistance to acidic medium and displays enhanced adsorption capacity [14].

CS is also considered as a promising material to removal pollutants. Extensive work has been performed to investigate the ability of chitosan and its derivatives for pharmaceutical compounds (PhCs) adsorption purposes. For example, the adsorption of PhCs, in three classes as anti-biotics, anti-inflammatory, nonsteroidal and other PhCs, from aqueous solution using diverse CS-based adsorbents was reviewed [15]. The high adsorption capacity of chitosan adsorbent composite for diclofenac uptake using EPCS@PEI adsorbent composite has been reported by Liakos et al. [14]. A magnetic Chitosan- $\mathrm{Fe}_{3} \mathrm{O}_{4}$ composite was successfully synthesized and used for the elimination of two PhCs (diclofenac sodium (DCF) and tetracycline hydrochloride) from water [16].

The textural properties of CS can be improved in combination with other polymers such as polyaniline (PANI). Moreover, PANI finds large applications in preparing adsorbent materials and photo-catalysts through doping, assembling composites and chemical modifications. The PANI functions such as imine and amine could react efficaciously with diverse contaminants molecule in polluted water, making it promising materials for waste-water treatment [17-19]. However, its industrial applications are limited by some obstacles like little processability and reduced mechanical properties. One process to surmount this disadvantage for workable applications is to functionalize PANI into CS. After functioning, the mechanical properties and the resistance to acidic medium will be ameliorated [20]. Consequently, the active binding-sites will be completely exposed. Lately, investigators have given significant attention in formation of various PANI@biopolymeric composites, according to their large applications in environmental science [21]. These composites provided a greater adsorbent capacity for anion/oxyanion [21]. But, to our knowledge, PANI functionalized by CS (PANI@CS) as a hybrid material has never been utilized as an adsorbent for the elimination of AAP from aqueous solution.

The object of this investigation was to simple develop, low-cost and environmentally benign process for elimination of AAP from aqueous solution by PANI, CS and PANI@CS adsorbent. Those products were characterized by BET, XPS, SEM, XRD, DTP, FTIR and TGA techniques. Moreover, the experimental variables affecting optimal adsorption were studied. Different isotherm models and adsorption kinetics also tested in detail. Finally, the recyclability of adsorbents was also examined.

\section{Experimental \\ 2.1. Materials}


All solutions were prepared with deionized $\mathrm{H}_{2} \mathrm{O}(18.2 \mathrm{M} \Omega . \mathrm{cm})$ obtained from an "Elga Labwater Purelab" system, Acetaminophen (AAP) (Sigma Aldrich, $\geq 97 \%$ ), Chitosan (CS) (Merck, Average molecular weight) was used as received, Aniline (ANI) (Merck, $\geq 99.5 \%$ ), Ammoniumpersulfate (APS) (Sigma Aldrich, $\geq 98 \%$ ), Ammonia solution $\left(\mathrm{NH}_{4} \mathrm{OH}\right)$ (Sigma Aldrich, 25\%), hydrochloric acid $(\mathrm{HCl})$ (Sigma Aldrich, 70\%), potassium hydroxide $(\mathrm{KOH})$ (Sigma Aldrich, 37\%), Ethanol $\left(\mathrm{C}_{2} \mathrm{H}_{5} \mathrm{OH}\right)($ Merck, $96 \%)$ and Filter paper (EAPI Company, Annaba, Algeria).

\subsection{Measurements}

The chemical composition and structure of the materials were recorded with a Fourier transform infrared spectrometer (FT-IR, Bruker Model Alpha, Germany) in a range of $4000-500 \mathrm{~cm}^{-1}$. X-ray diffraction (XRD) graphics were obtained by a diffractometer (Bruker-CCD-Apex) under $\mathrm{Cu}-\mathrm{K}_{\mathrm{a}}$ radiation. The surface morphology of adsorbents was obtained by scanning electron microscope (SEM; Hitachi S-4700). Thermal gravimetric analysis (TGA; STA-1500) was applied to examine the thermal stability of samples under nitrogen atmosphere with heating rate of $10^{\circ} \mathrm{C} \cdot \mathrm{min}^{-1}$. Electron binding energies of the elements were recorded on X-ray photoelectron spectroscopy (XPS; VG-3000 Electron), with monochromatic Al-Ka $X$-ray radiation. The TPDs were performed at $20^{\circ} \mathrm{C} \cdot \mathrm{min}^{-1}$ up to $900^{\circ} \mathrm{C}$ under a Helium flow $(100$ $\mathrm{mL} \cdot \mathrm{min}^{-1}$ ) in SDT/2960 Simultaneous equipment (TA-Apparatus) coupled to a MSC/200 mass spectrometer (Balzers. Thermostar). The adsorbents were heated up to $950\left(2^{\circ} \mathrm{C} \cdot \mathrm{min}^{-1}\right)$, and kept at this temperature for 60 minutes, under a Helium flow, and the type and amount of surface oxygen groups (CO and $\mathrm{CO}_{2}$ ) were characterized with a microgas chromatograph (Varian/490-GC). UV-Vis spectra were performed to calculate the AAP concentrations by Hitachi (U3000). The surface structure data were determined from the $\mathrm{N}_{2}$ adsorption-desorption isotherms at $77.2^{\circ} \mathrm{K}$ using instruments (ASAP-2020; Micromeritics). The Brunauer-Emmett-Teller (BET) surface area, pore volume and pore size distribution measurements were carried out by a $\mathrm{N}_{2}$ adsorption method applied Autosorb iQ. [18, 19].

\subsection{Adsorbents preparation}

The synthesis of PANI@CS adsorbent was performed according to the procedures reported by Mahi et al. [19]. $10 \mathrm{~g}$ of CS was dissolved into $200 \mathrm{~mL}$ of $\mathrm{HCl}(1 \mathrm{M})$ then $5 \mathrm{~mL}$ of aniline monomer was added. The resulting solution was left under stirring for 30 minutes to homogenize it (Solution A). Solution B (50 ml) of APS was prepared and was poured into solution A (resulting in $250 \mathrm{ml}$ ). The molar ratio of ANI:APS was 1:1. The resultant solution was kept at room temperature for 24 horas under $1100 \mathrm{rpm}$ stirring. Then, the precipitate was washed with $\mathrm{C}_{2} \mathrm{H}_{5} \mathrm{OH}$ and distilled $\mathrm{H}_{2} \mathrm{O}$ to eliminate the non-reacted compounds and dried at $70^{\circ} \mathrm{C}$ for $24 \mathrm{~h}$. For comparison, PANI synthesis was performed according to Bekhoukh et al. [18]. Generally, the proposed pathway of PANI@CS preparation was illustrated in Fig. 1.

\subsection{Adsorption tests in batch mode}

The stock solution $\left(\mathrm{S}_{\text {sol }}\right)$ of $1000 \mathrm{mg} \cdot \mathrm{L}^{-1}$ AAP was produced with a purity of $97 \%$. Required test concentrations were prepared by appropriate dilution of the $S_{\text {sol }}$. The adsorption kinetics was investigated 
at $\mathrm{pH}$ of the solution in a thermo-stated bath at $298 \mathrm{~K}$, utilizing $50 \mathrm{~mL}$ of different AAP concentrations put in contact with $5 \mathrm{mg}$ of adsorbent (PANI, CS and PANI@CS). The samples were agitated for various times (10 to $2160 \mathrm{~min}$ ), and then the solutions were filtered and tested using UV-Vis spectroscopy at a detection wavelength of $242 \mathrm{~nm}$. The adsorption isotherm were examined out at $\mathrm{pH}$ of the solution; a $50 \mathrm{~mL}$ volume of different initial concentrations of AAP solution $\left(100-20000 \mathrm{mg} \cdot \mathrm{L}^{-1}\right)$.

The $\mathrm{pH}$ influence was investigated using Erlen beaker that contain $50 \mathrm{~mL}$ of AAP solution with a concentration of $15000 \mathrm{mg} \cdot \mathrm{L}^{-1}$ at pH between 2 and 12. The solutions were agitated for $1440 \mathrm{~min}$ at $298 \mathrm{~K}$. The initial $\mathrm{pH}$ values of these solutions has been adjusted by adding $(0.1 \mathrm{~N}) \mathrm{HCl}$ or $(0.1 \mathrm{~N}) \mathrm{KOH}$.

The temperature impact was studied out at $298 \mathrm{~K}, 303 \mathrm{~K}, 313 \mathrm{~K}$ and $318 \mathrm{~K}$ at same conditions as adsorption at 298K. The removal efficiency and the adsorption capacity were determined using the equations are presented in Table 1. Where; $C_{0}\left(\mathrm{mg}^{\mathrm{L}} \mathrm{L}^{-1}\right)$ : initial AAP concentration and $C_{e q}\left(\mathrm{mg} \cdot \mathrm{L}^{-1}\right)$ : residual AAP concentration. $V(\mathrm{~L})$ : solution volume, $m(\mathrm{~g})$ : adsorbent mass.

Table 1

The mathematical expressions of adsorption

\begin{tabular}{|c|c|}
\hline Expressions & Linearized Form \\
\hline Removal efficiency & $R \%=\frac{\left(C_{0}-C_{e q}\right)}{\bar{C}_{0}} .100$ \\
\hline Adsorption capacity & $Q_{e q}=\frac{\left(C_{0}-C_{e q}\right) V}{m}$ \\
\hline Langmuir isotherm & $\frac{C_{e q}}{Q_{e q}}=\frac{1}{K_{l} C_{m}}+\frac{C_{e q}}{Q_{m}}$ \\
\hline Freundlich isotherm & $L n Q_{e q}=L n K_{f}+\frac{1}{n} L n C_{e q}$ \\
\hline Pseudo-first order (PFO) & \\
\hline Pseudo-second order (PSO) & \\
\hline Van't Hoff law & $\operatorname{Ln}\left(\frac{Q_{e q}}{C_{e q}}\right)=-\frac{\Delta H}{R T}+\frac{\Delta S}{\bar{R}}$ \\
\hline Gibbs free energy & $\Delta G=\Delta H-T \Delta S$ \\
\hline
\end{tabular}

Adsorption isotherm showed how adsorbate react with adsorbent and so are important in improving the usage of adsorbent materials. So, the correlation of equilibrium values by either mathematical or experimental relations is significant for empirical design and employment of adsorption processes. To develop the most favorable correlation for empirical equilibrium values, the two most common isotherm laws (Langmuir \& Freundlich) were investigated [22, 23]: 
The Langmuir isotherm is valid to homogeneous adsorption operations where the surface of the adsorbent are uniform, that is, all removal sites are equal, there are no interactions among adsorbed species and only mono-layer creation is probable. The linear formula of the Langmuir equation can be displayed in Table 1. Where; $Q_{e q}\left(\mathrm{mg}^{-\mathrm{g}^{-1}}\right)$ : adsorbed amount, $C_{e q}\left(\mathrm{mg} \cdot \mathrm{L}^{-1}\right)$ : Equilibrium concentrations of adsorbate, $Q_{m}\left(\mathrm{mg} \cdot \mathrm{g}^{-1}\right)$ : maximum adsorption capacity and $K_{l}\left(\mathrm{~L} . \mathrm{mg}^{-1}\right)$ : Langmuir constants.

Both multi-layer (physi-sorption) and monolayer (chemi-sorption) can be defined using the Freundlich isotherm. This class is founded on adsorbent surface by the heterogeneous equilibrium. The formula for Freundlich isotherm is in Table 1. Where; $\mathrm{n}$ and $K_{f}\left(\mathrm{mg}^{1-1 / \mathrm{n}} \cdot \mathrm{L}^{1 / \mathrm{n}} \cdot \mathrm{g}^{-1}\right)$ : Freundlich constants, $C_{e q}\left(\mathrm{mg} \cdot \mathrm{L}^{-1}\right)$ : equilibrium concentrations.

\subsection{Adsorption kinetic}

The kinetics studies was performed out with an overall contact time of $36 \mathrm{~h}$ for AAP adsorption taking the initial concentrations of $15000 \mathrm{mg} \cdot \mathrm{L}^{-1}$, adjusting the $\mathrm{pH}$ at 7.0. PFO and PSO models were considered to explicate the kinetics adsorption mechanisms $[18,24]$. The linear using PFO and PSO equations are illustrated in Table 1. Where; $Q_{t}\left(\mathrm{mg} \cdot \mathrm{g}^{-1}\right)$ : AAP concentration at time $(\mathrm{t}), Q_{e}\left(\mathrm{mg} \mathrm{g}^{-1}\right)$ : equilibrium concentration, $k_{1}\left(\mathrm{~min}^{-1}\right)$ : PFO rate constant of adsorption, $k_{2}\left(\mathrm{~g} \cdot \mathrm{mg}^{-1} \cdot \mathrm{min}\right)$ : PSO rate constant, $k_{2} Q_{e}{ }^{2}$ (g.mg $\left.{ }^{-1} \cdot \mathrm{min}\right)$ : initial rate adsorption.

\subsection{Adsorbent regeneration tests}

The reusability of CS, PANI and PANI@CS, the adsorbent materials that exhibited superior overall performance, was evaluated using a five cycle adsorption test. About $0.5 \mathrm{~g}$ of adsorbent were mixed with $50 \mathrm{~mL}$ of a $15000 \mathrm{mg} \cdot \mathrm{L}^{-1}$ AAP solution and shaken at room temperature for $24 \mathrm{~h}$. The pH was adjusted to obtain a neutral range at equilibrium conditions and these tests were also done in triplicates. After the end of the adsorption cycle, the adsorbent was separated, followed by elution with $\mathrm{C}_{2} \mathrm{H}_{5} \mathrm{OH}$ and distilled water.

\section{Results And Discussion}

\subsection{Physicochemical characterization}

The surface area and also poresize distribution of adsorbents were examined by the BET way (Fig. 2-a). The three samples displayed the isotherm of type-III. The calculated $\mathrm{S}_{\mathrm{BET}}$ of PANI, CS and PANI@CS are $46 \mathrm{~m}^{2} \cdot \mathrm{g}^{-1}, 988 \mathrm{~m}^{2} \cdot \mathrm{g}^{-1}$ and $1008 \mathrm{~m}^{2} \cdot \mathrm{g}^{-1}$, respectively. The $\mathrm{S}_{\mathrm{BET}}$, mesoporous volume and total pore of materials are given in Table 2. The $\mathrm{S}_{\mathrm{BET}}$ value is more important for hybrid adsorbent versus to $\mathrm{CS}$ and PANI which confirms the existence of more activated surface sites for PANI@CS [25]. 
Table 2

Textural characterization and Surface composition (at\%) from XPS of adsorbents prepared before and after adsorption.

\begin{tabular}{|lllllll|}
\hline Adsorbents & \multicolumn{3}{l}{ Before adsorption } & \multicolumn{3}{l|}{ After adsorption } \\
\cline { 2 - 6 } & PANI & CS & PANI@CS & PANI & CS & PANI@CS \\
\hline $\mathrm{S}_{\mathrm{BET}} / \mathrm{m}^{2} \cdot \mathrm{g}^{-1}$ & 46 & 988 & 1008 & 25 & 51 & 64 \\
\hline $\mathrm{V}_{\mathrm{DR}}\left(\mathrm{N}_{2}\right) / \mathrm{cm}^{3} \cdot \mathrm{g}^{-1}$ & 1.82 & 1197 & 2.10 & 1.02 & 82 & 1.54 \\
\hline $\mathrm{V}_{\text {mes }} / \mathrm{cm}^{3} \cdot \mathrm{g}^{-1}$ & 0.02 & 0.31 & 0.30 & 0.01 & 0.19 & 0.28 \\
\hline $\mathrm{V}_{\text {mic }} / \mathrm{cm}^{3} \cdot \mathrm{g}^{-1}$ & 0.01 & 0.43 & 0.44 & 0.01 & 0.08 & 0.13 \\
\hline $\mathrm{V}_{\text {tot }}$ pore & 0.03 & 0.74 & 0.74 & 0.02 & 0.27 & 0.41 \\
\hline
\end{tabular}

To confirm the molecular structure of adsorbents, XPS analysis was carried out for three samples prepared. In Fig. 2-b, for the wide scan of the samples the peaks at $284 \mathrm{eV}, 398 \mathrm{eV}$ and $530 \mathrm{eV}$ for C, N and 0 . Table 3 illustrates measured chemical composition of specimens. Moreover, the C1S peak of CS adsorbent is divided into three parts, at $284.59 \mathrm{eV}, 286.06 \mathrm{eV}$ and $288.30 \mathrm{eV}$ (Fig. 3-a). The peaks indicate the $\mathrm{C}-\mathrm{C}, \mathrm{C}-\mathrm{OH}$ and $\mathrm{O}-\mathrm{C}-\mathrm{O}$ bonds, respectively; and these obtained values are exactly matched with available literature [26, 27]. In addition, we can notice these peaks exist in both CS and PANI@CS. Moreover, Fig. 3-c displays the deconvoluted high resolution C1s spectrum of PANI@CS. The XPS spectrum can be deconvoluted into four components, at $284.56 \mathrm{eV}, 285.66 \mathrm{eV}, 286.94 \mathrm{eV}$ and $290.96 \mathrm{eV}$, respectively. The main peak at $284.56 \mathrm{eV}$ is assigned to the $\mathrm{C}-\mathrm{C} / \mathrm{C}-\mathrm{H}$ groups present in polymers. The peaks at $285.66 \mathrm{eV}$ and $286.94 \mathrm{eV}$ are due to $\mathrm{C}-\mathrm{N}$ and $\mathrm{C}-\mathrm{OH}$ groups due to the hydroxyl groups which are incorporated between CS and PANI. There is shake-up satellite at $290.96 \mathrm{eV}$, due to the existence of $\mathrm{C}-\mathrm{N}$ groups. 
Table 3

XPS data of Binding Energy (BE) for adsorbents prepared.

\begin{tabular}{|c|c|c|c|c|}
\hline \multirow[t]{2}{*}{ Species } & \multicolumn{3}{|c|}{ Adsorbents and $\mathrm{BE}(\mathrm{eV})$} & \multirow[t]{2}{*}{ Observation } \\
\hline & CS & PANI & PANI@CS & \\
\hline \multirow[t]{3}{*}{$01 \mathrm{~s}$} & 531.74 & $/ /$ & 531.35 & $\mathrm{C}=\mathrm{O}, \mathrm{O}=\mathrm{C}-\mathrm{OH}$ \\
\hline & $/ /$ & 532.33 & 532.50 & $\mathrm{C}-\mathrm{OH}$ \\
\hline & 533.41 & 533.57 & 533.74 & $\mathrm{H}_{2} \mathrm{O}$ \\
\hline \multirow[t]{4}{*}{ C1s } & 284.59 & 284.60 & 284.56 & $\mathrm{C}=\mathrm{C}, \mathrm{C}-\mathrm{H}, \mathrm{C}-\mathrm{C}$ \\
\hline & $/ /$ & 285.91 & 285.66 & $\mathrm{C}-\mathrm{O}, \mathrm{C}-\mathrm{N}$ \\
\hline & 286.06 & 287.73 & 286.94 & $\mathrm{C}-\mathrm{OX}, \mathrm{N}-\mathrm{C}=\mathrm{N}$ \\
\hline & 288.30 & $/ /$ & 290.96 & O-C-O \\
\hline \multirow[t]{3}{*}{ N1s } & $/ /$ & 399.74 & 399.44 & $=\mathrm{N}-$ \\
\hline & 400.95 & 401.11 & 400.63 & $-\mathrm{NH}-$ \\
\hline & 402.51 & $/ /$ & 401.84 & $-\mathrm{NH}_{\mathrm{x}}$ \\
\hline
\end{tabular}

The N1s XPS spectrum of CS is shown in Fig. 3-d. The results indicated the peaks at 400.95 and 402.51 $\mathrm{eV}$ assigning to the assignments of $-\mathrm{NH}$ - and $-\mathrm{NH}_{\mathrm{x}}$ groups, respectively. Further, based on the $\mathrm{N} 1 \mathrm{~s}$ values in PANI@CS (Fig. 3-f), characterized by XPS it was concluded that there peaks observed at $401.84 \mathrm{eV}$, $400.63 \mathrm{eV}$ and $399.44 \mathrm{eV}$ which can be attributed to $-\mathrm{NH}_{\mathrm{x}},-\mathrm{NH}-$ and $=\mathrm{N}-$ groups, respectively. This result suggests that blending PANI with CS produced a hybrid absorbent with more amino functional groups on surface [28].

To further investigate of the different adsorbents prepared, the overall nitrogen content was determined. The surface elemental compositions from the XPS analysis are listed in Table 4. The PANI@CS, shows a nitrogen content of $10.80 \%$ in the surface layer. Moreover, the XPS analysis of CS adsorbent reveals a significantly less total nitrogen content compared with other adsorbents prepared. The content difference is obviously due to the new structure. Further, this nitrogen content obtains indicated that the matrix PANI were well-dispersed in the CS during the polymerization. 
Table 4

Surface composition of the adsorbents obtained by TPD and XPS.

\begin{tabular}{|lllllll|}
\hline Adsorbents & \multicolumn{3}{l}{ TPD / $\mathrm{mmol}^{-1}$} & \multicolumn{4}{l|}{ XPS / at.\% } \\
\cline { 2 - 7 } & $\mathrm{CO}$ & $\mathrm{CO}_{2}$ & $\mathrm{O}_{\text {tot }}$ & $\mathbf{0}$ & $\mathbf{C}$ & $\mathbf{N}$ \\
\hline CS & 1975 & 513 & 3000 & 28.75 & 67.66 & 3.59 \\
\hline PANI@CS & 1485 & 355 & 2190 & 16.09 & 73.11 & 10.80 \\
\hline
\end{tabular}

The surface chemistry of those adsorbents has been also investigated by thermal programmed desorption (TPD), which presents more detailed description about the quantity and nature of surface oxygen (O) groups [29]. The quantity of $\mathrm{O}$ groups that transferred as $\mathrm{CO}, \mathrm{as}^{\mathrm{CO}}$ and the resulting quantity of $\mathrm{O}$ in adsorbents have been compiled in Table 4. The CS adsorbent possesses a large amount of oxygen functionalities that decompose mainly as $\mathrm{CO}$ and in lower extent as $\mathrm{CO}_{2}$ (Fig. 2-c and Fig. 2-d). The PANI matrix produces the attachment of nitrogen to the surface of the CS by consumption of oxygen functional groups [30], as confirmed by XPS (Table 4). Thus, PANI@CS has lower oxygen content than the pristine CS adsorbent.

The FT-IR spectra of PANI@CS, CS and PANI before AAP retention are used as a reference for interpreting any possible structural changes (Fig. 4). FT-IR spectrum of CS presents adsorption bands at 1021, 1084 and $1153 \mathrm{~cm}^{-1}$ are due to $\mathrm{C}-\mathrm{O}$ stretching vibration of primary alcoholic groups, $\mathrm{C}-\mathrm{N}$ stretching vibration and saccharide unit of CS. The vibration bands at 1021 and $1153 \mathrm{~cm}^{-1}$ disappear after AAP adsorption. It can be seen also the stretching vibration at 1387 and $1456 \mathrm{~cm}^{-1}$ indicating amide III (C-N stretching) and aromatic $\mathrm{C}-\mathrm{C}$ stretch, respectively. These latter bands turn to a single band at $1393 \mathrm{~cm}^{-1}$ after AAP adsorbed. On the other hand, a vibration bands at 1625 and $2872 \mathrm{~cm}^{-1}$ characteristic of $\mathrm{C}=0$ stretching on the bond $\left(-\mathrm{NHCO}-\mathrm{CH}_{3}\right)$ and $\mathrm{C}-\mathrm{H}$ stretching of $\mathrm{CH}_{2}$ groups, respectively. The $-\mathrm{OH}$ and $-\mathrm{NH}$ stretching is between 3100 and $3400 \mathrm{~cm}^{-1}$ [32]. Moreover, in hybrid adsorbent typical bands of PANI were found at $806 \mathrm{~cm}^{-1}$ due to $\mathrm{C}-\mathrm{C}$ stretching of quinoid rings and deformation of the benzenoid rings respectively. The band at $1207 \mathrm{~cm}^{-1}$ for PANI appeared due to $\mathrm{C}=\mathrm{N}$ stretching vibration. The transmittance peak at 1326 $\mathrm{cm}^{-1}$ owing $\mathrm{C}-\mathrm{N}$ bond, $1516 \mathrm{~cm}^{-1}$ due to $\mathrm{C}=\mathrm{C}$ stretching vibration of benzenoid rings, $1573 \mathrm{~cm}^{-1}$ due to stretching vibration of quinoid rings. The bands between the ranges $3000-3500 \mathrm{~cm}^{-1}$ ascribed to secondary amines stretching $(\mathrm{N}-\mathrm{H})$ vibrations [21]. The FT-IR spectra of PANI@CS adsorbent displays the next bands at $3426,2878,1657,1578,1317$ and $1078 \mathrm{~cm}^{-1}$. Compared to CS, the functional groups moved to a higher frequency band. On the contrary, the peaks at 1516 and $1208 \mathrm{~cm}^{-1}$ were disappeared. These modifications confirm that significant amounts of $\mathrm{O}-\mathrm{H}$ and $\mathrm{N}-\mathrm{H}$ at CS were grafted by PANI [21]; while most of the bands changed their positions after absorption.

The XRD patterns of all adsorbents were recorded in Fig. 5-a. The diffraction pattern of CS displays two peaks at $2 \theta=10.36^{\circ}$ and $20.78^{\circ}$ indicating the ordered crystalline structure of CS. Moreover, PANI is semicrystalline in nature as the patterns show three peaks centered at $2 \theta=7.41^{\circ}(011), 20.21^{\circ}(020)$, and 
$25.91^{\circ}$ (200) because of the presence of B with Q group in the polymer chain [31]. Moreover, the XRD pattern of PANI@CS displays different crystalline structure with small moves associating together to PANI and CS, which further confirmed the succeeded grafting of PANI backbone with CS chain [16, 18, 22], in the peaks positions. It is distinctly seen from XRD study that the hybrid material offer an amorphous in nature with a little crystalline part from $2 \theta=10^{\circ}$ to $30^{\circ}$. The CS crystallinity has been reduced after surface grafted by PANI backbone and this can be because the intermolecular forces into structure of composite formed, which is predicted for the elimination of AAP [21].

The TGA thermograms of CS, PANI and PANI@CS are present in Fig. 5-b. The TGA curve of CS displays two stages of weight loss, the first occurring in the range of 25 to $160^{\circ} \mathrm{C}$ attributed to loss of $\mathrm{H}_{2} \mathrm{O}$ molecules with the weight loss approximately $3.49 \%$. The primary degradation of CS started at $230^{\circ} \mathrm{C}$ and it was completely degraded at near $900^{\circ} \mathrm{C}$ with a weight loss of almost $13.27 \%$ [34]. TGA of PANI@CS presented three different steps of weight loss. The first step starting from 25 to $160^{\circ} \mathrm{C}$, can attributed to the loss of adsorbed $\mathrm{H}_{2} \mathrm{O}$ with a weight loss of almost 7.59\%. The second decomposition step occurs between $220^{\circ} \mathrm{C}$ and $450^{\circ} \mathrm{C}$, correspond to degradation (approximately $23.96 \%$ ). The third step of the TGA curve is after $500^{\circ} \mathrm{C}$ to $900^{\circ} \mathrm{C}$ with a weight loss of almost $13.78 \%$. These values prove the loss of the thermal stability for PANI@CS compared to the CS, confirming the formation of the hybrid adsorbent.

The SEM image of CS presents full amorphous regions as illustrated in (Fig. 6-a). The image clearly depicts the surface of CS is coarse and consisting of holes and uneven lumps that make it suitable for adsorption [35]. The SEM micrographs of PANI@CS as shown in (Fig. 6-b), reveal that the inclusion of PANI chain has great influence on morphology of the adsorbents that result in an interlocking arrangement of material. A close investigation of the surface reveals that PANI matrix is uniformly distributed on CS forming a network interconnecting each other and distributed on the entire surface during the polymerization process.

\subsection{Adsorption assessments 3.2.1. Effect of $\mathrm{pH}$}

$\mathrm{pH}$ is one of the most significant parameters for adsorption process since the surface charge of molecules changes according the $\mathrm{pH}$ of the environment [18]. Thus, the influence of $\mathrm{pH}$ on the AAP adsorption by the three adsorbents was tested. The plot showing the adsorption of AAP on CS, PANI and PANI@CS is given in Fig. 7-a. The results of CS showed that adsorption efficiency increased as pH increased from 2.0 to 6.0 . After increasing $\mathrm{pH}$ to 7.0 , the adsorption percent slightly increased, and then it is quickly decreased to $\mathrm{pH} 12.0$ values. However, for PANI, the adsorption percent decreased as the $\mathrm{pH}$ is increased. Obviously, PANI@CS has a higher affinity for AAP adsorption rather than both CS and PANI overall investigated $\mathrm{pH}$ range. Thereby, the deposition of PANI matrix on the CS surface is a efficacious strategy to ameliorate its AAP uptake ability. Moreover, it can be inferred that the imine and amine groups in PANI@CS hybrid adsorbent act as very helpful hosts to bind AAP from the aqueous solution. For the increase from 7.0 to 12.0, the capacity decreased for all adsorbents prepared. This behaviour is linked to 
the dissociation of functional groups on the adsorbent surface at $\mathrm{pH}$ above $6.0\left(\mathrm{pK}_{\mathrm{a}}=9.5\right)$, causing adsorbate and adsorbent to be negatively charged. In this condition, electrostatic repulsion happens between the adsorbent and adsorbate molecules, causing the elimination to be disadvantaged [36]. This behaviour is in accord with other studies reporting the adsorption of AAP [36, 37]. Thereby, pH 7.0 was suggested as an optimum $\mathrm{pH}$ value for experiments of sorption of the studied AAP from aqueous solutions.

\subsubsection{Effect of contact time}

The shaking time between adsorbed and adsorbent is an essential role, as it enables us to know more in detail the characteristics, the design of the adsorption process, the mechanism as well as the adsorbate adsorption ratio and equilibrium time [38]. The influence of the time on the adsorption was studied and the equilibrium time was determined in the experiments carried out with the most suitable adsorbents with maximum adsorption capacity at $\mathrm{pH} 7.0$ at $25^{\circ} \mathrm{C}$ (Fig. 7-b). As can be seen from the figure, at the end of 480 min, AAP adsorption to CS and PANI@CS reached the maximum level with values 359.84 $\mathrm{mg} . \mathrm{g}^{-1}$ and $383.48 \mathrm{mg} \cdot \mathrm{g}^{-1}$, respectively. In the adsorption processes, it is expected that equilibrium will be established between the adsorbent and the substance to be removed after a certain period of time. Because the functional groups on the adsorbent material reach fullness, the adsorption reaches equilibrium after a certain period of time $[18,19]$. On the other hand, it is observed that the maximum adsorption $\left(242.84 \mathrm{mg}^{-1} \mathrm{~g}^{-1}\right.$ ) on PANI was achieved within only $360 \mathrm{~min}$.

\subsubsection{Adsorption kinetics}

Figure 7-b. illustrates the impact of contact time on AAP adsorption by CS, PANI and PANI@CS with $15000 \mathrm{mg} \cdot \mathrm{L}^{-1}$ initial concentration. The AAP was noted to rapidly achieve equilibrium (300 min) by PANI. However, onto CS and PANI@CS, AAP need longer contact time (480 min) to arrive equilibrium. The augmentation in equilibrium time with hybrid adsorbent is because to the increased contest for new active sites of the PANI@CS.

Adsorption kinetics of AAP on materials obtained was studied by using pseudo-1st -order (PFO) and pseudo-2nd -order (PSO) laws. The adsorption kinetics have been investigated in the initial concentration of $15000 \mathrm{mg} \cdot \mathrm{L}^{-1}$.

The PFO explains the adsorption happens between solid and liquid system depending to the elimination capability of adsorbent materials were expressed by the relations are presented in Table 1. Where; $Q_{e}$ (mg.g $\left.\mathrm{g}^{-1}\right)$ : equilibrium concentration, $Q_{t}\left(\mathrm{mg}^{-1} \mathrm{~g}^{-1}\right)$ : concentration at time $t, k_{1}\left(\mathrm{~min}^{-1}\right)$ : PFO rate constant of adsorption. PFO linear regression plot of $\log \left(C_{e}-C_{t}\right)$ versus $t$ presents a weak correlation coefficients (Table 5) displaying that the PFO kinetic was not succeed by adsorption. 


\section{Table 5}

PFO and PSO kinetics for AAP elimination on adsorbents at pH:7.0, 298K and $C_{0}: 15000 \mathrm{mg}^{-\mathrm{L}^{-1}}$.

\begin{tabular}{|c|c|c|c|c|c|c|c|}
\hline \multirow[t]{2}{*}{ Adsorbents } & \multirow{2}{*}{$\begin{array}{l}Q_{\text {eq.Exp }} \\
\left(\mathrm{mg} \cdot \mathrm{g}^{-1}\right)\end{array}$} & \multicolumn{3}{|l|}{ PFO } & \multicolumn{3}{|l|}{ PSO } \\
\hline & & $\begin{array}{l}k_{1} \\
\min ^{-1}\end{array}$ & $\begin{array}{l}Q_{e q . C a l} \\
\mathrm{mg.g}\end{array}$ & $R^{2}$ & $\begin{array}{l}k_{2 . a d s} \\
\text { g. } \mathrm{mg}^{-1} \cdot \mathrm{min}^{-1}\end{array}$ & $\begin{array}{l}Q_{e q . C a l} \\
\mathrm{mg.g}^{-1}\end{array}$ & $R^{2}$ \\
\hline PANI & 242.49 & 0.0103 & 214.48 & 0.78 & 0.00015 & 196.08 & 0.94 \\
\hline CS & 359.84 & 0.0066 & 298.26 & 0.57 & 0.00026 & 208.33 & 0.97 \\
\hline PANI@CS & 385.25 & 0.0129 & 348.01 & 0.92 & 0.00088 & 344.82 & 0.98 \\
\hline
\end{tabular}

The PSO kinetic shows a chemisorption phenomenon from solutions [43]. Also, the linear formula is written by the relations are presented in Table 1 . Where; $k_{2}\left(\mathrm{~g} \cdot \mathrm{mg}^{-1} \cdot \mathrm{min}\right)$ : PSO rate constant, $Q_{t}\left(\mathrm{mg} \cdot \mathrm{g}^{-1}\right)$ : concentration at time $t, Q_{e}\left(\mathrm{mg} \cdot \mathrm{g}^{-1}\right)$ : adsorption capacity, $k_{2} Q_{e}^{2}\left(\mathrm{~g} \cdot \mathrm{mg}^{-1} \cdot \mathrm{min}\right)$ : initial adsorption rate.

The PFO and PSO kinetic data are calculated taking into account the correlation values $\left(R^{2}\right)$. According to Table 5, the adsorption kinetic of AAP by three adsorbents is better defined by the PSO kinetics data than the PFO models because of the high $R^{2}$. This shows that AAP removal by CS and PANI are dominated by chemical adsorption [43].

The adsorption rate values measured based on PSO kinetic are $88_{\square} 10^{-5}, 26_{\square} 10^{-5}$ and $15_{\square} 10^{-5}$ g.mg ${ }^{-1} \cdot \mathrm{min}^{-1}$ for PANI@CS, CS and PANI, respectively, reflecting a faster adsorption process by hybrid adsorbent. This is possibly because the better feasibly accessible to active sites of hybrid material compared with other adsorbents used. This augments the electrostatic attraction between PANI@CS adsorbent and AAP molecules, consequent a speed adsorption rate. Several investigators illustrated the succeeded usage of the PSO equation for the represent empirical kinetics values of AAP adsorption by several materials adsorbent (Table 6) [4, 8, 12, 36-44]. 
Table 6

The adsorptive capacity of several adsorbents for removal of AAP

\begin{tabular}{|llll|}
\hline Adsorbents & Adsorption Efficiency & pH & Ref. \\
\hline AC from Oak acorn & 45.45 & 3.0 & {$[4]$} \\
\hline Chemically modified Orange peel & 28.09 & $/ /$ & {$[8]$} \\
\hline SAC from Biomass waste & 356.22 & 5.0 & {$[12]$} \\
\hline AC from Butia capitata & 100.60 & 7.0 & {$[36]$} \\
\hline NH4Cl-induced AC & 233.00 & 7.1 & {$[37]$} \\
\hline ABSAC & 145.40 & 8.0 & {$[38]$} \\
\hline AC from Dende coconut & 70.62 & 2.0 & {$[39]$} \\
\hline AC from Babassu coconut & 71.39 & 2.0 & {$[39]$} \\
\hline Rice husk ash & 7.65 & 8.0 & {$[40]$} \\
\hline Chemically Modified AC & 75.00 & 6.5 & {$[41]$} \\
\hline AC Pellets & 105.00 & 7.0 & {$[42]$} \\
\hline Commercial AC & 261.04 & 7.0 & {$[43]$} \\
\hline AC from Fly ash & 270.30 & 7.0 & {$[44]$} \\
\hline PANI@CS & 385.25 & 7.0 & This work \\
\hline
\end{tabular}

\subsection{Adsorption isotherm modeling}

The monolayer adsorption capacity, the amount adsorbed was measured by the linear equation presented in Table 1, where $Q_{e q}\left(\mathrm{mg} \mathrm{g}^{-1}\right)$ : amount adsorbed, $C_{e q}\left(\mathrm{mg} \cdot \mathrm{L}^{-1}\right)$ : equilibrium concentration of the adsorbate, $Q_{m}\left(\mathrm{mg}^{-1} \mathrm{~g}^{-1}\right)$ : maximum adsorption capacity of adsorbent and $K_{/}\left(\mathrm{L}_{\mathrm{mg}} \mathrm{m}^{-1}\right)$ : Langmuir constant.

Both multilayer (physisorption) and monolayer (chemisorption) can be measured using the Freundlich isotherm. This model is based on the heterogeneous equilibrium on adsorbents surface. The formula for Freundlich isotherm is illustrated in Table 1, where; $n$ and $K_{f}\left(\mathrm{mg}^{1-1 / \mathrm{n}} \cdot \mathrm{L}^{1 / \mathrm{n}} \cdot \mathrm{g}^{-1}\right)$ : Freundlich isotherm constant and $C_{e q}\left(\mathrm{mg} \cdot \mathrm{L}^{-1}\right)$ : equilibrium concentration.

Basically, the adsorption phenomenon of porous adsorbent possesses three steps. First, the pollutant moved from solution to adsorbents surface by a liquid-boundary film. Secondly, this pollutant moved from adsorbents surface to intraparticle active site and finally, a strong interaction of pollutant molecules with the disposable sites on both the internal and external surfaces of adsorbents [45]. 
As a result of the adsorption studies carried out at the specified concentrations, the maximum AAP concentration to be adsorbed by different adsorbents was determined by plotting the amount of adsorbed AAP against the concentration values (Fig. 7-c). As display in Table 7, the fitting data of Langmuir equation for AAP adsorption were better than Freundlich equation, which exhibited the adsorption phenomenon, appertained to a chemisorption adsorption. And the $n$ value $(n>1)$ of Freundlich equation confirmed that the three adsorbents was conducive to absorb AAP. As a result, this model is unable to justify the experimental capacity for AAP where the values of $K_{f}$ obtained from this model are significantly lower than the experimental values, as shown in Table 7. Also, the $R^{2}$ values were smaller than those obtained from the Langmuir model. Thus, the Freundlich model does not fully explain the experimental results for these elements [46]. Combined with the kinetics and isotherm analysis data, the chemisorption was prevailing on adsorption of AAP by adsorbents prepared.

Table 7

Langmuir \& Freundlich isotherms constants for AAP removal by adsorbents at pH:7.0 and 298K.

\begin{tabular}{|c|c|c|c|c|c|c|c|}
\hline \multirow[t]{2}{*}{ Adsorbents } & \multicolumn{4}{|l|}{ Langmuir } & \multicolumn{3}{|l|}{ Freundlich } \\
\hline & $Q_{m}\left(\mathrm{mg} \cdot \mathrm{g}^{-1}\right)$ & $K_{L}\left(\mathrm{~L} \cdot \mathrm{mg}^{-1}\right)$ & $R_{L}$ & $R^{2}$ & $K_{F}\left(\mathrm{mg}^{1-1 / \mathrm{n}} \mathrm{L}^{1 / \mathrm{n}} \mathrm{g}^{-1}\right)$ & $n$ & $R^{2}$ \\
\hline PANI & 101.01 & 0.087 & 0.101 & 0.99 & 28.64 & 5.21 & 0.71 \\
\hline CS & 243.90 & 0.539 & 0.007 & 0.99 & 45.84 & 3.27 & 0.75 \\
\hline PANI@CS & 196.08 & 0.024 & 0.172 & 0.98 & 30.95 & 4.33 & 0.76 \\
\hline
\end{tabular}

Temperature effects on the adsorption of AAP by PANI, CS and PANI@CS adsorbed from aqueous solution with $\mathrm{pH} 7.0$ were investigated at different temperatures in the range from 25 to $45^{\circ} \mathrm{C}$. In Fig. 7-d, it can be found that the AAP adsorption decreases with increasing temperature. In the adsorption process the thermodynamic parameters of enthalpy change $\Delta \mathrm{H}$, free energy change $\Delta \mathrm{G}$ and entropy change $\Delta \mathrm{S}$ can be measured by the formulas presented in Table 1, where; $\Delta \mathrm{S}\left(\mathrm{kJ}^{\mathrm{mol}}{ }^{-1}\right)$ : entropy, $\Delta \mathrm{H}\left(\mathrm{kJ}^{\mathrm{mol}}{ }^{-1}\right)$ : enthalpy, $\mathrm{T}(\mathrm{K})$ : absolute temperature and $\mathrm{R}\left(8.314 \mathrm{~J} \cdot \mathrm{mol}^{-1} \cdot \mathrm{K}^{-1}\right)$ : general gas constant.

The negative values $\Delta \mathrm{G}$ displays the adsorption of AAP molecules by CS adsorbent is extremely favorable (Table 8 ). Furthermore, $\Delta \mathrm{G}$ values are found to decrease with the augmentation of temperature is proved the spontaneous character of the adsorption processes at increased temperatures, this may demonstrated that the increased of adsorbents pores and more surface modification. The $\Delta \mathrm{H}$ positive values illustrate the endothermic character of the elimination and it may also exhibit the adsorption processes physiosorption. The increasing positive values of $\Delta \mathrm{S}$ at higher temperature may because to the increasing mobility and reducing the size of AAP which causes to increase in kinetics energy of the AAP. It favors the fast diffusion of AAP towards the adsorbents [47]. The same way was followed in the case of 
PANI and PANI@CS adsorbents, which confirmed that the bonding between AAP and adsorbents related to formation of PANI matrix on CS surface.

Table 8

Thermodynamic data for the AAP adsorption by the adsorbents prepared.

\begin{tabular}{|c|c|c|c|c|}
\hline Adsorbents & $\mathrm{T} / K$ & $\Delta G / \mathrm{kJ}^{\mathrm{mol}}{ }^{-1}$ & $\Delta H / \mathrm{kJ}^{\mathrm{mol}} \mathrm{F}^{-1}$ & $\Delta S / \mathrm{kJ} \mathrm{mol}^{-1}$ \\
\hline \multirow[t]{4}{*}{ PANI } & 298 & -10.17 & \multirow[t]{4}{*}{29.05} & \multirow[t]{4}{*}{0.131} \\
\hline & 303 & -10.81 & & \\
\hline & 313 & -12.16 & & \\
\hline & 318 & -12.79 & & \\
\hline \multirow[t]{4}{*}{ CS } & 298 & -9.18 & \multirow[t]{4}{*}{27.86} & \multirow[t]{4}{*}{0.123} \\
\hline & 303 & -9.46 & & \\
\hline & 313 & -10.05 & & \\
\hline & 318 & -12.01 & & \\
\hline \multirow[t]{4}{*}{ PANI@CS } & 298 & -9.01 & \multirow[t]{4}{*}{25.25} & \multirow[t]{4}{*}{0.114} \\
\hline & 303 & -9.34 & & \\
\hline & 313 & -10.20 & & \\
\hline & 318 & -11.46 & & \\
\hline
\end{tabular}

\subsection{Proposed adsorption mechanism}

The proposed elimination mechanism of hybrid adsorbent preparation and adsorption of AAP on their surface are sketched in Fig. 1. According to the available functional groups on the PANI@CS surface, the adsorption mechanism of AAP by PANI@CS can be ascribed to the various interactions. Firstly, the electrostatic bonding was ruled out due to the AAP $\left(\mathrm{pK}_{\mathrm{a}} \approx 9.5\right)$ was not ionized under solution $\mathrm{pH} 7.0$; an analogous conclusion was reported in the literature [48]. On the other hand, the presence of the chemical bond between nitrogen species and AAP, and Van der Waals forces in the elimination was certain (Fig. 8a), however this weak forces was recognized as a less significant contributor in adsorption mechanisms [49]. In fact, the $n-\pi$ bonding and also known as "donor-acceptor complex mechanism" (Fig. 8-b) is generally occurred where the lone pair electrons on an oxygen or nitrogen atom are delocalized into the $\pi$-orbital of an benzene ring of AAP $[49,50]$.

\subsection{Regeneration study}

The regeneration has been investigated in a specific manner for all the adsorbents since the renewability may be crucially important and significant parameters for holding the processes costs down and reduce wastes. Please refer to the experimental section above for details. Generally, the adsorption capacity of 
adsorbents progressively decreases as the cycles number increases as illustrated in Fig. 9, which is fundamentally assigned to the incomplete, desorption of AAP during the renovation processes, thereby causing a decrease in adsorption active sites [51]. Moreover, the PANI@CS showed slightly diminishing in the adsorption capacity after five cycles of adsorption-desorption processes above $68 \%$, which is because hybrid adsorbent has an additional cavity resulting from the formation of polymer matrix on the CS surface, indicating the structural stability and reusability of the optimized PANI@CS. Moreover, the adsorption capacity of PANI decreased from $75.89-25.16 \%$ after also five cycles. Nevertheless, the adsorption capacity of CS for AAP still reaches $52.82 \%$ after 5 -cycles, indicating that CS also has acceptable renovability and recyclability compared to PANI.

\section{Conclusions}

In this study, CS supported on PANI matrix was synthesized through a simple polymerization method and its preparation was proved by surface area, XPS, TPD, XRD, FTIR, TGA and SEM analysis. The PANI@CS displays exceptional porosity, thermal stability and renewability. After the most suitable adsorbs was synthetized for adsorption, the rest of the experiments were carried out on these adsorbents. In the second stage of the study, the effect of $\mathrm{pH}$, adsorption equilibrium time, temperature and AAP initial concentration on adsorption were investigated. The maximum adsorption capacity of PANI@CS, CS and PANI were found to be $385.25 \mathrm{mg} \cdot \mathrm{g}^{-1}, 359.84 \mathrm{mg} \cdot \mathrm{g}^{-1}$ and $242.49 \mathrm{mg} \cdot \mathrm{g}^{-1}$, respectively; at $25^{\circ} \mathrm{C}$ and optimal $\mathrm{pH} 7.0$, which was best than that of other adsorbents published in literature. The kinetics and isotherm model corresponds to PSO and Langmuir formulas. This displays that the adsorption processes of AAP is chemisorption. The adsorption phenomenon can proceeds spontaneously and appertain to the endothermic process according to the thermodynamic data. Moreover, the good performances adsorption is mainly due to the $\mathrm{H}$-bonding, $\pi \pi$ bonding, pore filling and chemisorption as possible mechanism for the elimination of AAP by PANI@CS. Significantly, hybrid adsorbent has good selectivity towards the AAP and fabulous regeneration behaviour. With the good selectivity, elevated adsorption capacity and outstanding renewability, the PANI@CS adsorbent could be a favorable candidate to AAP adsorb from wastewater.

\section{Declarations}

\section{Acknowledgements}

The authors would like to thank Algerian MESRS for the opportunity to bring their work to life and also IUMA of Alicante Spain for the co-operation availing.

Funding information: In this work, no financial sources funding.

Conflict of Interest: There are no conflicts to declare.

\section{References}


1. F.J.G. Mateos, R.R. Rosas, M.D. Marqués, L.M. Cotoruelo, J.R. -Mirasol, T. Cordero, Removal of paracetamol on biomass-derived activated carbon: modeling the fixed bed breakthrough curves using batch adsorption experiments. Chemical Engineering Journal. 279, 18-30 (2015)

2. A. Peng, M. Huang, Z. Chen, C. Gu, Oxidative coupling of acetaminophen mediated by $\mathrm{Fe}^{3+}-$ saturated montmorillonite. Science of the Total Environment. 595, 673-680 (2017)

3. N. Sivarajasekar, N. Mohanraj, K. Balasubramani, J.P. Maran, I.G. Moorthy, V. Karthik, K. Karthikeyan. Optimization, equilibrium and kinetic studies on ibuprofen removal onto microwave assistedactivated Aegle marmelos correa fruit shell. Desalination and Water Treatment. 84, 48-58 (2017)

4. H. Nourmoradi, K. Moghadam, A. Jafari, B. Kamarehie, Removal of acetaminophen and ibuprofen from aqueous solutions by activated carbon derived from Quercus Brantii (Oak) acorn as a low-cost biosorbent. Journal of Environmental Chemical Engineering. 6, 6807-6815 (2018)

5. M.S. Fram, K. Belitz, Occurrence and concentrations of pharmaceutical compounds in groundwater used for public drinking-water supply in California. Science of the Total Environment. 409, 34093417 (2011)

6. D.R. Lima, A.H. Bandegharaei, P.S. Thued, E.C. Lima, Y.R.T. de Albuquerque, G.S. dos Reisa, C.S. Umpierres, S.L.P. Diasa, H.N. Tran, Efficient acetaminophen removal from water and hospital effluents treatment by activated carbons derived from Brazil nutshells. Colloids and Surfaces A. 583, 123966 (2019)

7. J. Zur, D. Wojcieszynska, K.H. Kocurek, A. Marchlewicz, U. Guzik, Paracetamol-toxicity and microbial utilization. Pseudomonas moorei KB4 as a case study for exploring degradation pathway. Chemosphere. 206, 192-202 (2018)

8. I.C. Afolabi, S.I. Popoola, O.S. Bello, Modeling pseudo-second-order kinetics of orange peelparacetamol adsorption process using artificial neural network. Chemometrics and Intelligent Laboratory Systems. 203, 104053 (2020)

9. R. Lafi, L. Gzara, R.H. Lajimi, A. Hafiane. Title, Treatment of textile wastewater by a hybrid ultrafiltration/electrodialysis process Treatment of textile wastewater by a hybrid ultrafiltration/electrodialysis process. Chemical Engineering and Processing - Process Intensification. 132, 105-113 (2018)

10. J.J.S. Alonso, N. El Kori, N.M. Martel, B.D.R. Gamero, Removal of ciprofloxacin from seawater by reverse osmosis. Journal of Environmental Management. 217, 337-345 (2018)

11. A. Mirzaei, Z. Chen, F. Haghighat, L. Yerushalmi, Removal of pharmaceuticals from water by homo/heterogonous Fenton-type processes: a review. Chemosphere. 174, 665-688 (2017)

12. L. Spessato, K.C. Bedin. A.L.Cazetta, I.P.A.F. Souza, V.A. Duarte, L.H.S. Crespo, M.C. Silva, R.M. Pontes, V.C. Almeida, $\mathrm{KOH}$-super activated carbon from biomass waste: Insights into the paracetamol adsorption mechanism and thermal regeneration cycles. Journal of Hazardous Materials. 371, 499505 (2019)

13. P. Sirajudheen, V.C.R. Kasim, C.P. Nabeena, M.C. Basheer, S. Meenakshi, Tunable photocatalytic oxidation response of ZnS tethered chitosan-polyaniline composite for the removal of organic 
pollutants: A mechanistic perspective. Materials Today. 47, 2553-2559 (2021)

14. E.V. Liakos, M. Lazaridou, G. Michailidou, I. Koumentakou, D.A. Lambropoulou, D.N. Bikiaris, G.Z. Kyzas. Chitosan Adsorbent Derivatives for Pharmaceuticals Removal from Effluents. A Review. Macromol. 1, 130-154 (2021)

15. H.K. Maleh, A. Ayati, R. Davoodi, B. Tanhaei, F. Karimi, S. Malekmohammadi, Y. Orooji, L. Fu, M. Sillanpää. Recent advances in using of chitosan-based adsorbents for removal of pharmaceutical contaminants: A review. Journal of Cleaner Production. 291, 125880 (2021)

16. S. Zhang, Y. Dong, Z. Yang, W. Yang, J. Wu, C. Dong, Adsorption of pharmaceuticals on chitosanbased magnetic composite particles with core-brush topology. Chemical Engineering Journal. 304, 325-334 (2016)

17. N. Wang, J. Li, W. Lv, J. Feng, W. Yan, Synthesis of polyaniline/TiO2 composite with excellent adsorption performance on acid red G. RSC Advances. 5, 21132-21141 (2015)

18. A. Bekhoukh, I. Moulefera, F.Z. Zeggai, A. Benyoucef, K. Bachari. Anionic Methyl Orange Removal from Aqueous Solutions by Activated Carbon Reinforced Conducting Polyaniline as Adsorbent: Synthesis, Characterization, Adsorption Behavior, Regeneration and Kinetics Study. Journal of Polymers and the Environment. doi.org/10.1007/s10924-021-02248-6

19. O. Mahi, K. Khaldi, M.S. Belardja, A. Belmokhtar, A. Benyoucef, Development of a New Hybrid Adsorbent from Opuntia Ficus Indica $\mathrm{NaOH}$ Activated with PANI Reinforced and Its Potential Use in Orange G Dye Removal. Journal of Inorganic and Organometallic Polymers and Materials. 31, 20952104 (2021)

20. V. Janaki, B.T. Oh, K. Shanthi, K.J. Lee, A.K. Ramasamy, S.K. Kannan, Polyaniline/chitosan composite: An eco-friendly polymer for enhanced removal of dyes from aqueous solution. Synthetic Metals. 162, 974-980 (2012)

21. S. Sahnoun, M. Boutahala, Adsorption removal of Tartrazine by Chitosan/Polyaniline composite: kinetics and equilibrium studies. International Journal of Biological Macromolecules. 114, 13451353 (2018)

22. S. Lagergren, Zur Theorie der Sogenannten Adsorption Gelöster Stoffe, Kungliga Svenska Vetenskapsakademiens. Handlingar. 24 (1898) 1-39

23. A. Spaltro, M.N. Pila, D.D. Colasurdo, E.N. Grau, G. Román, S. Simonetti, D.L.Ruiz. Removal of paracetamol from aqueous solution by activated carbon and silica. Experimental and computational study. Journal of Contaminant Hydrology. 236, 103739 (2021)

24. I. Toumi, H. Djelad, F. Chouli, A. Benyoucef, Synthesis of PANI@ZnO Hybrid Material and Evaluations in Adsorption of Congo Red and Methylene Blue Dyes: Structural Characterization and Adsorption Performance. Journal of Inorganic and Organometallic Polymers and Materials. doi.org/10.1007/s10904-021-02084-0

25. S.P. Gupta, H.H. Nishad, S.D. Chakane, S.W. Gosavi, D.J. Late, P.S. Walke, Phase transformation in tungsten oxide nanoplates as a function of post-annealing temperature and its electrochemical influence on energy storage. Nanoscale Advances. 2, 4689-4701 (2020) 
26. P.C. Li, G.M. Liao, S.R. Kumar, C.M. Shih, C.C. Yang, D.M. Wang, S.J.e Lue. Fabrication and Characterization of Chitosan Nanoparticle Incorporated Quaternized Poly(Vinyl Alcohol) Composite Membranes as Solid Electrolytes for Direct Methanol Alkaline Fuel Cells. Electrochimica Acta. 187, 616-628 (2016)

27. B. Gieroba, A.S. Bartnicka, P. Kazimierczak, G. Kalisz, A.L. Graczyk, V. Vivcharenko, R. Nowakowski, I.S. Pieta, A. Przekora. Spectroscopic studies on the temperature-dependent molecular arrangements in hybrid chitosan/1,3- $\beta$-D-glucan polymeric matrices. International Journal of Biological Macromolecules. 159, 911-921 (2020)

28. Z. Zheng, Y. Wei, G. Wang, A.W.Q. Ao, Y. Gong, X. Zhang, Surface properties of chitosan films modified with polycations and their effects on the behavior of PC12 cells. Journal of Bioactive and Compatible Polymers. 24, 63-82 (2009)

29. F.Q. Plata, R.R. Rosas, E. Morallón, D.C. Amorós, Activated carbons prepared through $\mathrm{H}_{3} \mathrm{PO}_{4}$-assisted hydrothermal carbonization from biomass wastes: porous texture and electrochemical performance. ChemPlusChem. 81, 1349-1359 (2016)

30. M.J.M. López, D.S. Torres, R.R. Rosas, E. Morallón, D.C. Amorós, Nitrogen-Doped Superporous Activated Carbons as Electrocatalysts for the Oxygen Reduction Reaction. Materials. 12, 1346 (2019)

31. J.P. Pouget, M.E. Józefowicz, A.J. Epstein, X. Tang, A.G. MacDiarmid, X-ray structure of polyaniline. Macromolecules. 24, 779-789 (1991)

32. J. Zhang, Q. Zhou, L. Ou, Kinetic, Isotherm, and Thermodynamic Studies of the Adsorption of Methyl Orange from Aqueous Solution by Chitosan/Alumina Composite. Journal of Chemical \& Engineering Data 57, 412-419 (2012)

33. C.N. Kedir, D.S. Torres, A.F.Q. Jaime, A. Benyoucef, E. Morallon, Hydrogels obtained from Aniline and Piperazine: Synthesis, characterization and their application in hybrid supercapacitors. Journal of Molecular Structure. 1248, 131445 (2022)

34. S. Kumar, P.K. Dutta, J. Koh, A physiocochemical and biological study of novel chitosanchloroquinoline derivative for biomedical applications. Int. J. Biol. Macromol. 49, 356-361 (2011)

35. A. Elahi, M. Irfan, A. Shakoor, N.A. Niaz, K. Mahmood, M. Qasim, Effect of loading titanium dioxide on structural, electrical and mechanical properties of polyaniline nanocomposites. J. Alloy. Compd. 651, 328-332 (2015)

36. C.M. Kerkhoff, K.B. Martinello, D.S.P. Franco, M.S. Netto, J. Georgin, E.L. Foletto, D.G.A. Piccilli, L.F.O. Silva, G.L. Dotto, Adsorption of ketoprofen and paracetamol and treatment of a synthetic mixture by novel porous carbon derived from Butia capitata endocarp. Journal of Molecular Liquids. 339, 117184 (2021)

37. A.M. Salehi, G. Moussavi, Removal of acetaminophen from the contaminated water using adsorption onto carbon activated with $\mathrm{NH} 4 \mathrm{Cl}$. Desalination and Water Treatment 57, 12861-12873 (2016)

38. A.F.M. Streit, G.C. Collazzo, S.P. Druzian, R.S. .Verdi, E.L. Foletto, L.F.S. Oliveira, G.L. Dotto, Adsorption of ibuprofen, ketoprofen, and paracetamol onto activated carbon prepared from effluent treatment plant sludge of the beverage industry. Chemosphere. 262, 128322 (2021) 
39. R. Ferreira, H. De Lima, A. Cândido, O.C. Junior, P. Arroyo, K. De Carvalho, G.F. Gauze, M.A.S.D. Barros, Adsorption of paracetamol using activated carbon of dende and babassu coconut mesocarp. International Journal of Biological, Biomolecular, Agricultural, Food and Biotechnological Engineering. 9, 717-722 (2015)

40. A. Thakur, N. Sharma, A. Mann. Removal of ofloxacin hydrochloride and paracetamol from aqueous solutions: Binary mixtures and competitive adsorption. Materials Today: Proceedings. 28 (2020) 1514-1519

41. V. Bernal, A. Erto, L. Giraldo, J.C.M. Piraján, Effect of Solution pH on the Adsorption of Paracetamol on Chemically Modified Activated Carbons. Molecules. 22, 1032 (2017)

42. R.O. Perez, C.G.A. Madera, V.D. Blancas. 3D modeling of overall adsorption rate of acetaminophen on activated carbon pellets. Chemical Engineering Journal. 321, 510-520 (2017)

43. J. Lladó, C.L. Luque, B. Ruiz, E. Fuente, M.S. Sardans, A.D. Dorado, Role of activated carbon properties in atrazine and paracetamol adsorption equilibrium and kinetics. Process Safety and Environmental Protection. 95, 51-59 (2015)

44. M. Galhetas, A.S. Mestre, M.L. Pinto, I. Gulyurtlu, H. Lopes, A.P. Carvalho, Carbon-based materials prepared from pine gasification residues for acetaminophen adsorption. Chemical Engineering Journal. 240, 344-351 (2014)

45. H. Jin, Y. Zhang, Q. Wang, Q. Chang, C. Li, Rapid removal of methylene blue and nickel ions and adsorption/desorption mechanism based on geopolymer adsorbent. Colloid and Interface Science Communications. 45, 100551 (2021)

46. I.M. Ali, M. Khalil, H.A. Madbouly, A.M. Soliman, Efficient lanthanides adsorption using magnetic hydroxyapatite incorporated cobalt. Int. J. Environ. Anal. Chem. 8, 1-20 (2021)

47. S.E. Subramani, N. Thinakaran, Isotherm, kinetic and thermodynamic studies onthe adsorption behaviour of textile dyes ontochitosan. Process Safety and Environmental Protection. 106, 1-10 (2017)

48. D.T. Nguyen, H.N. Tran, R.S. Juang, N.D. Dat, F. Tomul, A. Ivanets, S.H. Woo, A.H. Bandegharaei, V.P. Nguyen, H.P. Chao, Adsorption process and mechanism of acetaminophen onto commercial activated carbon. Journal of Environmental Chemical Engineering 8, 104408 (2020)

49. A.H. Jawad, N.S.A. Mubarak, S. Sabar, Adsorption and mechanism study for reactive red 120 dye removal by cross-linked chitosan-epichlorohydrin biobeads. Desalination and Water Treatment 164, 378-387 (2019)

50. J.A. Mattson, H.B. Mark, M.D. Malbin, W.J. Weber, J.C. Crittenden, Surface chemistry of active carbon: specific adsorption of phenols. J. Colloid Interface Sci. 31, 116-130 (1969)

51. S. Wang, W. Chen, C. Zhang, H. Pan, Efficient and selective adsorption of cationic dyes with regenerated cellulose. Chemical Physics Letters. 784, 139104 (2021)

\section{Figures}




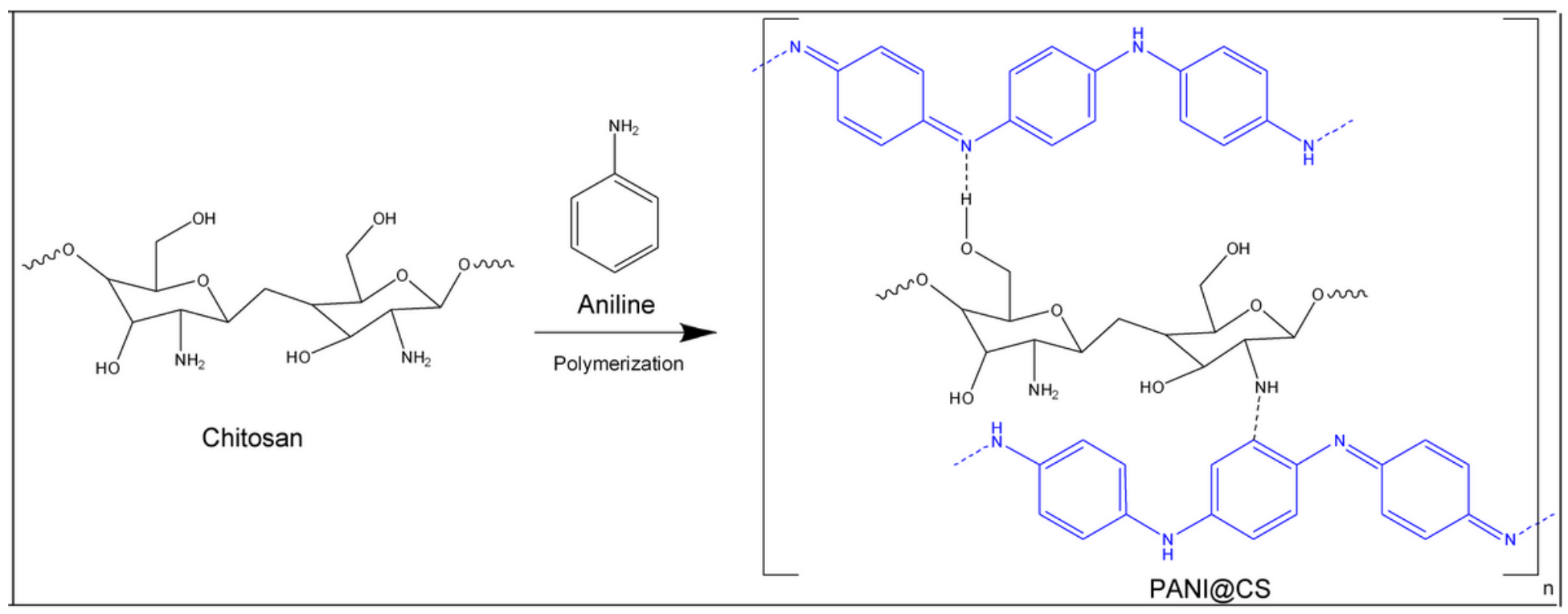

Figure 1

A graphical exemplification of the PANI@CS prepared.

Figure 2

(a) BET surface area, (b) Survey XPS spectra, (c) CO-TPD profiles and (d) $\mathrm{CO}_{2}$-TPD profiles of adsorbents

\section{Figure 3}

XPS spectral: (a) C1s of CS, (b) C1s of PANI, (c) C1s of PANI@CS, (d) N1s of CS, (e) N1s of PANI and (f) N1s of PANI@CS. 
PANI@CS (After)
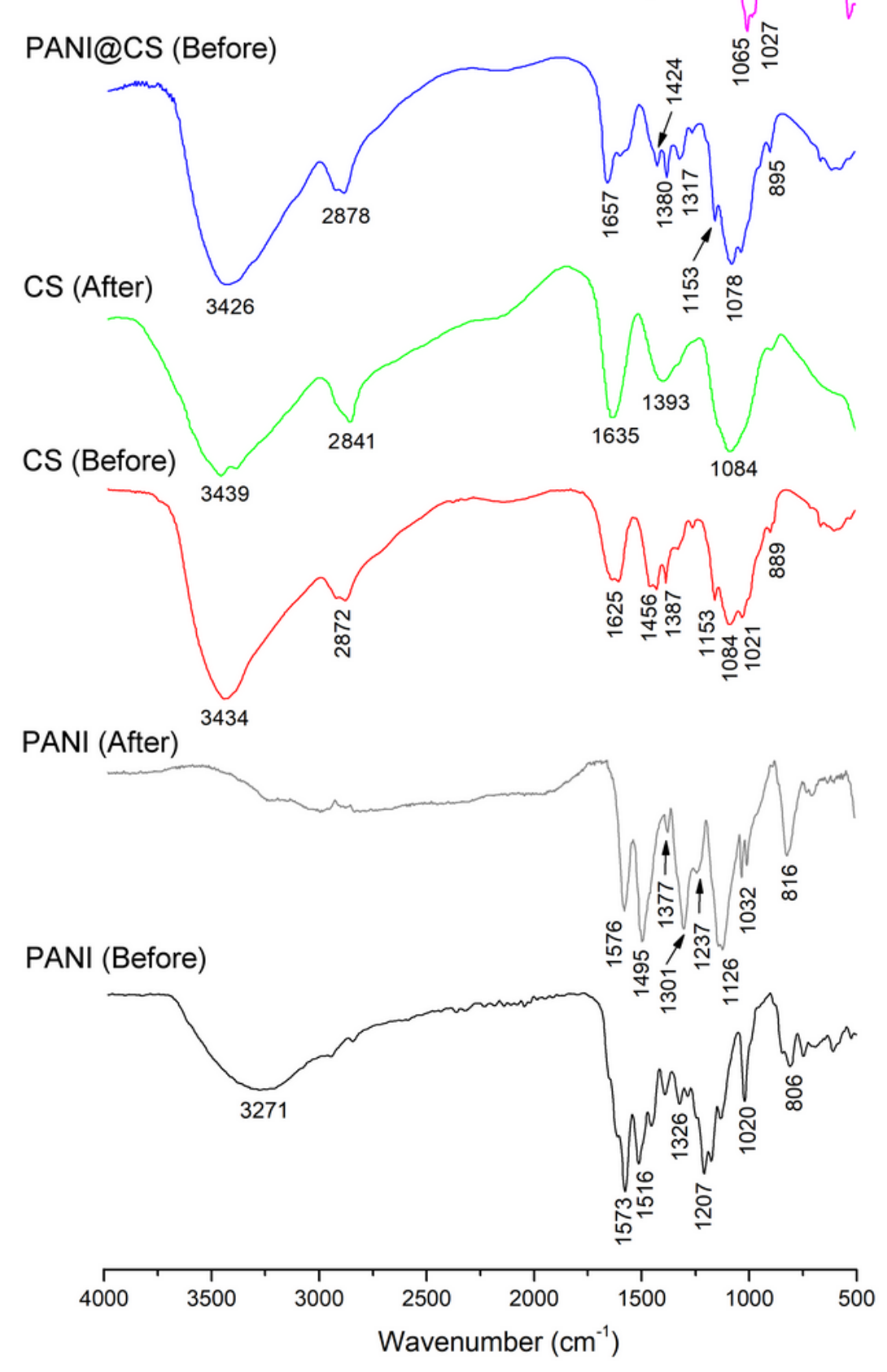

\section{Figure 4}

FTIR analysis of adsorbents before and after adsorption. 


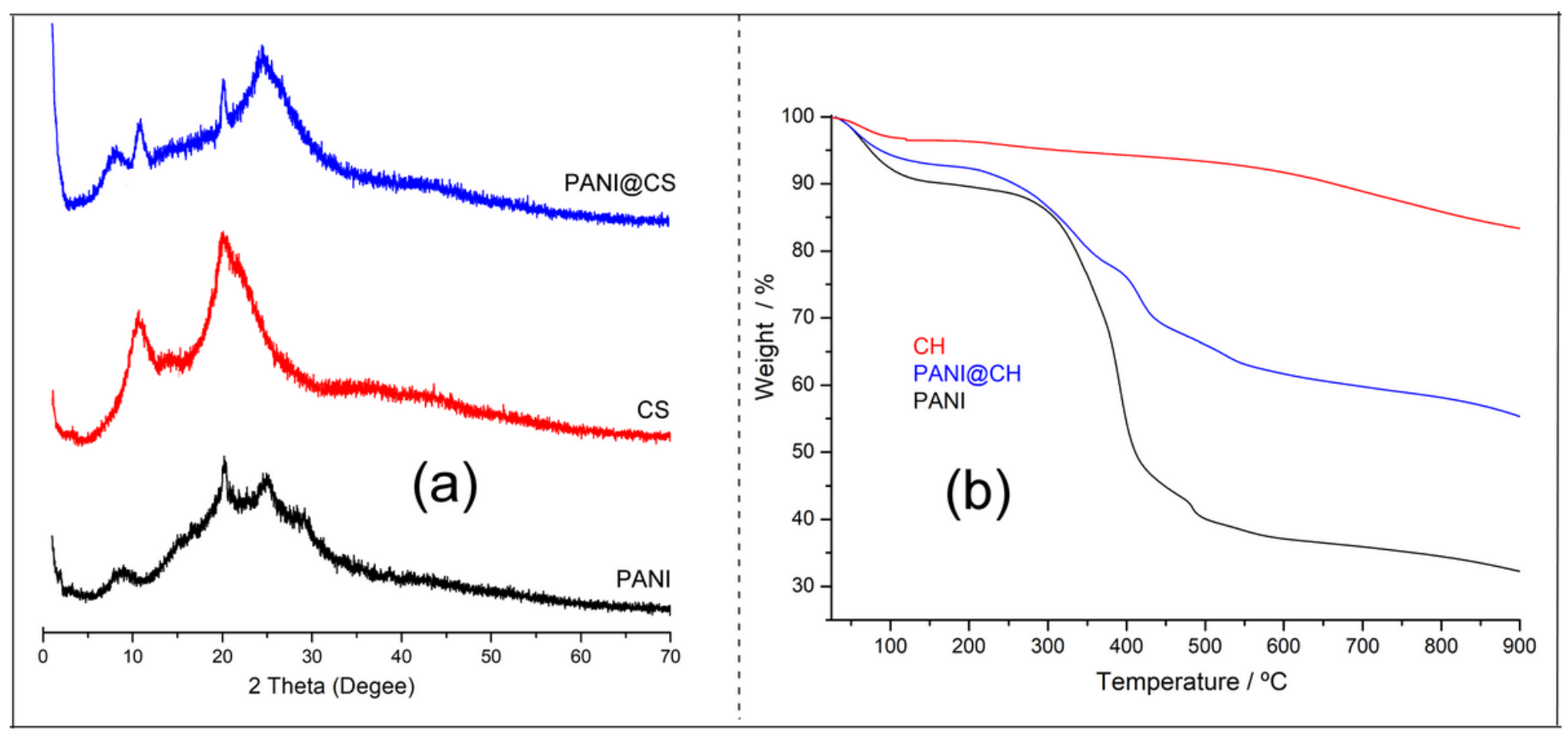

Figure 5

(a) XRD patterns and (b) TGA analysis of adsorbents.

Figure 6

SEM images of: (a) raw CS and (b) PANI@CS. 


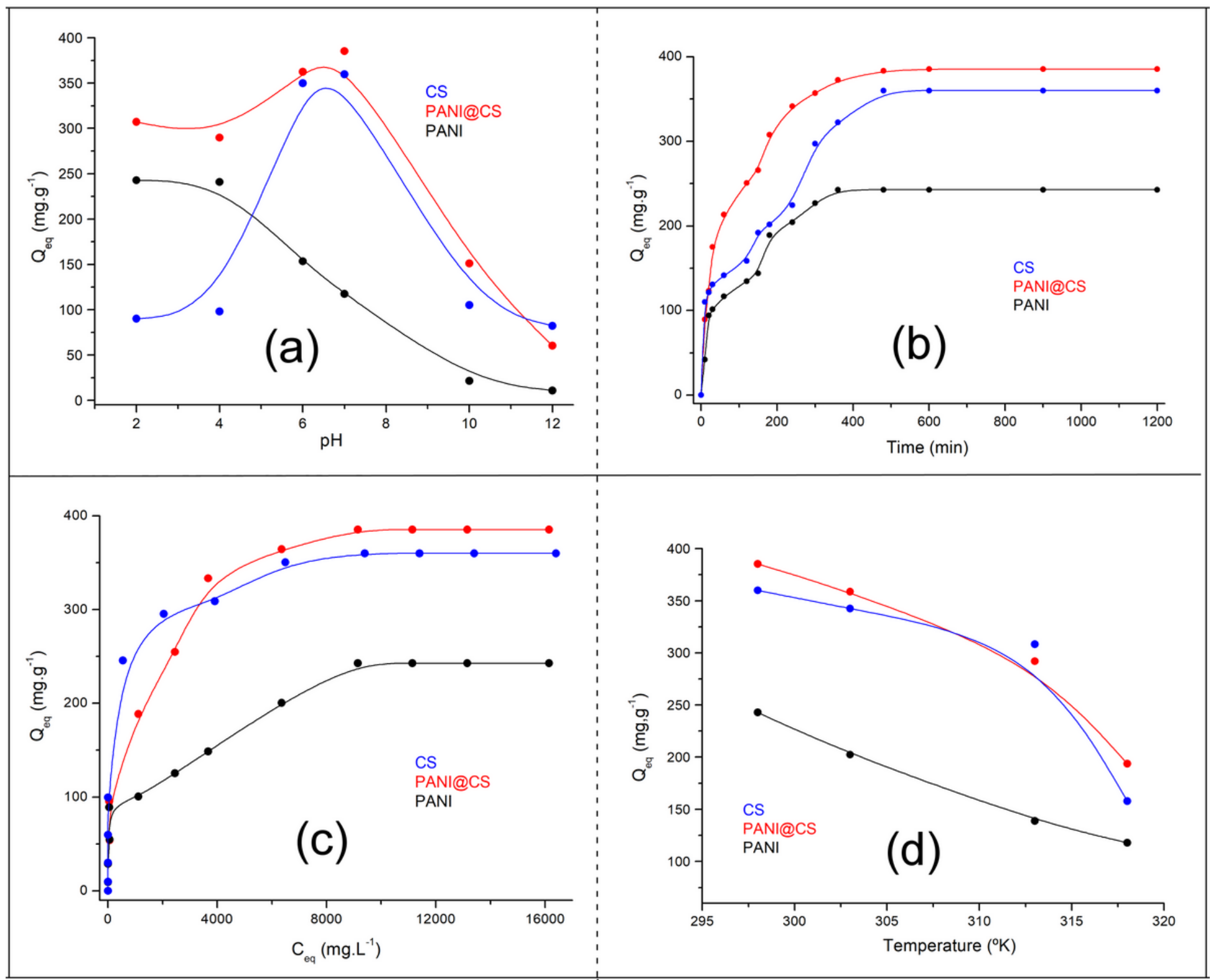

Figure 7

(a) Influence of pH on adsorption capacity, (b) Effect of contact time on the adsorption process, (c) Adsorption isotherm and (d) Influence of temperature on adsorption capacity (adsorbents dose: $0.1 \mathrm{~g}$; AAP: $\left.100 \mathrm{~mL} ; \mathrm{C}_{0}: 15000 \mathrm{mg} \cdot \mathrm{L}^{-1} ; \mathrm{T}: 298 \mathrm{~K} ; \mathrm{pH} 7.0\right)$.

\section{Figure 8}

Possible adsorption mechanism of various mods of interactions between AAP and PANI@CS: (a) Hbonding and (b) $n-\pi$ interactions. 


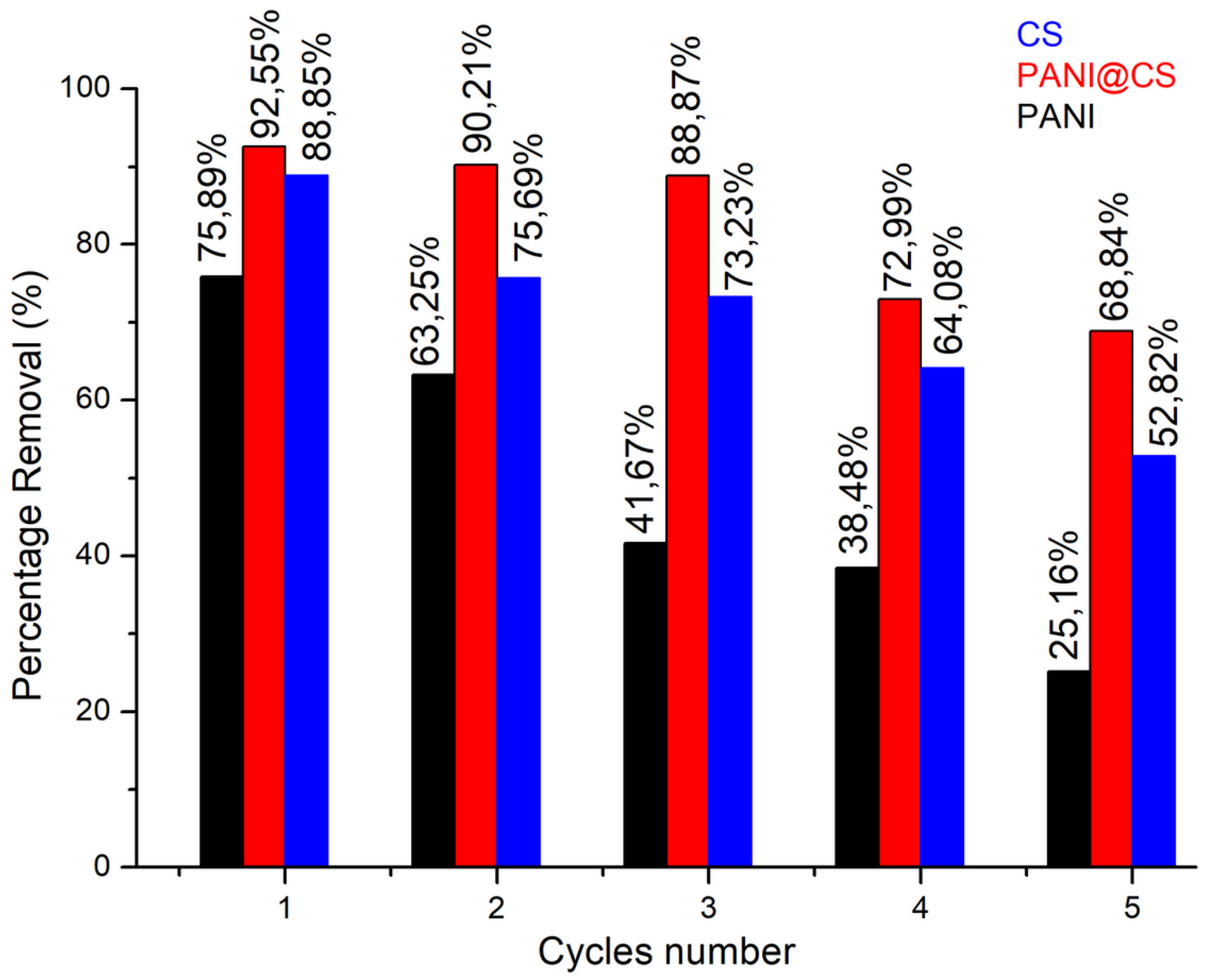

Figure 9

Cyclic adsorption-desorption performance of adsorbents on AAP (adsorbents dose: $0.1 \mathrm{~g} ;$ AAP: $100 \mathrm{~mL} ; \mathrm{C}_{0}$ : 15000 mg. L $^{-1} ; \mathrm{T}: 298 \mathrm{~K} ; \mathrm{pH} 7.0$ ). 